\title{
The interpretation of the figure of the prophet Jonah by Michelangelo on the ceiling of the sistine chapel: anatomical urological vision
}

Leonardo Oliveira Reis, Emerson Luis Zani, João Carlos Alonso, Fabiano André Simões, Ronald Finamore Rejowski, Gilson Barreto

School of Medical Sciences, University of Campinas - Unicamp (OLR, ELZ), Campinas and Urology Department of Municipal Hospital of Paulinia - HMP (LOR, JCA, FAS, RFR, GB), Paulinia, Brazil

\section{ABSTRACT}

Purpose: A detailed analysis in the iconography and pictorial appearance of the scene of the "Prophet Jonah" painted by the artist Michelangelo Buonarroti (14751564) on the ceiling of the Sistine Chapel between the years 1508 and 1512.

Materials and Methods: Literature review on the Italian Renaissance period and the life of Michelangelo Buonarroti and analysis of historical aspects of the evolution of studies of human anatomy in this period and the works of the artist.

Results: A comparative analysis of the representation of the figure of the fish on the left thigh of "Jonah" with a cross section of penis shows a curious similarity. The pictorial and iconographic analysis reveals an intensity of light on the pubic area and the position of the prophet with the legs spread apart and left hand placed on this region. A tube-shaped cloth covers the region and the angel at the side seems to be looking at this anatomical region of "Jonah". In fact, sets of iconographic and pictorial relate to the deciphered code.

Conclusions: This description helps to confirm the relationship of the Renaissance art with the human anatomy; science has been much studied in this period. The design of a cross section of the penis is revealed with the two cavernous bodies with the septum between them and the spongy body. Considering the circumstances in which Michelangelo had painted, subjectivity was fundamental due to religious motivations added to the vigorous implications of a limited scientific knowledge typical of that era.

\section{ARTICLE INFO}

\section{Key words:}

History; urology; art; anatomy; humans; penis; science

Int Braz J Urol. 2012; 38: 317-23

Submitted for publication:

October 27, 2011

Accepted after revision:

February 16, 2012

\section{INTRODUCTION}

Michelangelo Buonarroti (1475-1564) is a famous Italian Renaissance artist. In addition to famous sculptures as "Pieta" and "David", the artist painted the ceiling of the Sistine Chapel between the years 1508 and 1512 in Rome.

Michelangelo had a life-long interest in anatomy that began with his participation in pub- lic dissections in his early teens, when he joined the court of Lorenzo de' Medici and was exposed to its physician-philosopher members (1-4). These anatomic studies aided him in creating extremely accurate depictions of the human figure in his sculptures and paintings, notably the statue of "David" in Florence and paintings of "God" and other figures from the Book of Genesis in the Vatican's Sistine Chapel in Rome. 
The link of anatomy with several artists of this period is confirmed by binding studies of anatomy at the School of Fine Arts in Florence during the Renaissance. Scholars of this period believed that knowing the minutiae of the human anatomy could help artists to reproduce the human form in sculptures and paintings.

Sistine Chapel frescoes are considered one of the monumental achievements of Renaissance art. In the winter of 1511, Michelangelo entered the final stages of the Sistine Chapel project and painted 4 frescoes along the longitudinal apex of the vault, which completed a series of 9 central panels depicting scenes from the Book of Genesis. In 1990, Frank Lynn Meshberger reported that Michelangelo concealed an image of the brain in the first of these last 4 panels, namely, the "Creation of Adam", showing a sagittal section of the brain as the bottom of the figure of the creator (5). The Creation of Adam on the ceiling of the Sistine Chapel has long been recognized as one of the world's great art treasures.

Others researchers reported that Michelangelo appears to have hidden an image of the brainstem and spinal cord in a depiction of God in the final panel of this series, the Separation of Light From Darkness (6). These findings by a neurosurgeon and a medical illustrator, published in Neurosurgery, may explain long controversial and unusual features of one of the frescoes' figures. $\mathrm{Al}-$ though the vast majority of subjects in this painting are considered anatomically correct, art historians and scholars have long debated the meaning of some anatomical peculiarities seen on God's neck in the part of this painting.

The Separation of Light From Darkness is an important panel in the Sistine Chapel iconography because it depicts the beginning of Creation and is located directly above the altar. The authors propose that Michelangelo, a deeply religious man and an accomplished anatomist, intended to enhance the meaning of this iconographically critical panel and possibly document his anatomic accomplishments by concealing this sophisticated neuroanatomic rendering within the image of God (6).

An American renal physician reckoned to have found convincing evidence that Michelangelo was familiar with the anatomy and function of the kidneys (7). According to Eknoyan, the artist's interest in the kidney started when he became afflicted with urolithiasis and sought help from the most prominent physician in Rome, Realdo Colombo (8). In the painting "The Separation of Land and Water" on the ceiling of the Sistine Chapel, the mantle of the creator resembles a bisected right kidney (7).

Another panel in ceiling of Sistine Chapel is "The Figure of the Prophet Jonah". According to the Old Testament, "Jonah" stayed inside the belly of a whale (some translations call it a fish) for three days and three nights (Jonah, 1:17 - Bible), thus escaping death by drowning. The scene is located at one end of the vaulted ceiling of the Sistine Chapel. The prophet is depicted leaning back and turned slightly to the right, and he thus creates an unusual effect by "contradicting" the architecture of the ceiling. "Thanks to the strength of art, the vault, which is in fact curving toward the front, seems to be pushed back", described Vasari (1). We made a detailed analysis of the scene of the "Prophet Jonah" on the ceiling of the Sistine Chapel in the iconography and pictorial appearance with a cross section of the penis.

\section{MATERIALS AND METHODS}

Literature review on the Italian Renaissance period and historical aspects of the evolution of studies of human anatomy in this period and the life and works of the Michelangelo Buonarroti were analyzed. A detailed analysis of the iconographic and pictorial clues of the scene of the "Prophet Jonah" was made, with special attention to position of the figures, the direction the characters are looking at, the "movement"/position of the hands and the region of the body that is painted in lighter shades.

A detailed analysis of the scene of the "Prophet Jonah" on the ceiling of the Sistine Chapel in its iconography and pictorial appearance and its correlation to a design of a cross section of the penis was done.

\section{RESULTS}

A comparative analysis of the representation of the figure of the fish on the left thigh of "Jonah" with a cross section of penis shows a curi- 
ous similarity (Figure-1). The pictorial and iconographic analysis reveals an intensity of light on "Jonah's" pubic region; the prophet was positioned with his legs spread apart, and a tube-shaped cloth covers the region; the angel at the side seems to be looking at this anatomical region of "Jonah".

The fish painted next to "Jonah's" left thigh has an unusual aspect (the front part does not look like a mouth). Comparing this front part of the fish with a cross-section of the base of a penis, the two cavernous bodies can be seen with the septum between them and the spongy body. All these structures can be found in this detail of the painting of the fish.

Add to these evidences, a study of the Prophet Jonah by Michelangelo Buonarroti reveals that the artist portraited the prophet with the right hand over the genital area. A draft for the ceiling of Sistine Chapel not maintained on the original painting confirms the genital focus of the scene (Figure-2).

\section{DISCUSSION}

The art of the Renaissance, not satisfied with copying the nudes of antiquity, encouraged its contributors into anatomical dissection to better reproduce the body in their art. With time, traditional courses of instruction for aspiring artists actually included a study of human anatomy, not only for its external features, but also for that of its supporting structures. In fact, the Florentine Academy of Art was the first to institute an obligatory course in anatomy, in which aspiring artists copied directly from cadavers and skeletons (4,9-11). In Florence, according to the Statuta universitatis et studdi florentini de 1387, the painters and sculptors were accepted into the Consorteria dei Medici e degli Speziali in the year 1303. The artists were given the bodies of people who died of natural causes in Santa Maria Novella Hospital or in other hospitals of the city, while to doctors only two cadavers of criminals hanged of both sexes were supplied per year for the study of anatomy.

The reason for this uneven distribution was that while the artists were concerned only with the surface of cadavers, the doctors dissected them and destroyed all their parts. The church, of course, objected on principle to the desecration of the dead, but did allow for dissection of the cadavers of condemned criminals and even facilitated it. Cadavers were either stolen or made available through the

Figure 1 - The Figure of the Prophet Jonah on the ceiling of Sistine Chapel, by Michelangelo Buonarroti, highlighting a detail of the scene of the prophet Jonah and his correlation to a design of a cross section of the base of a penis, with the two cavernous bodies with the septum between them and the spongy body.

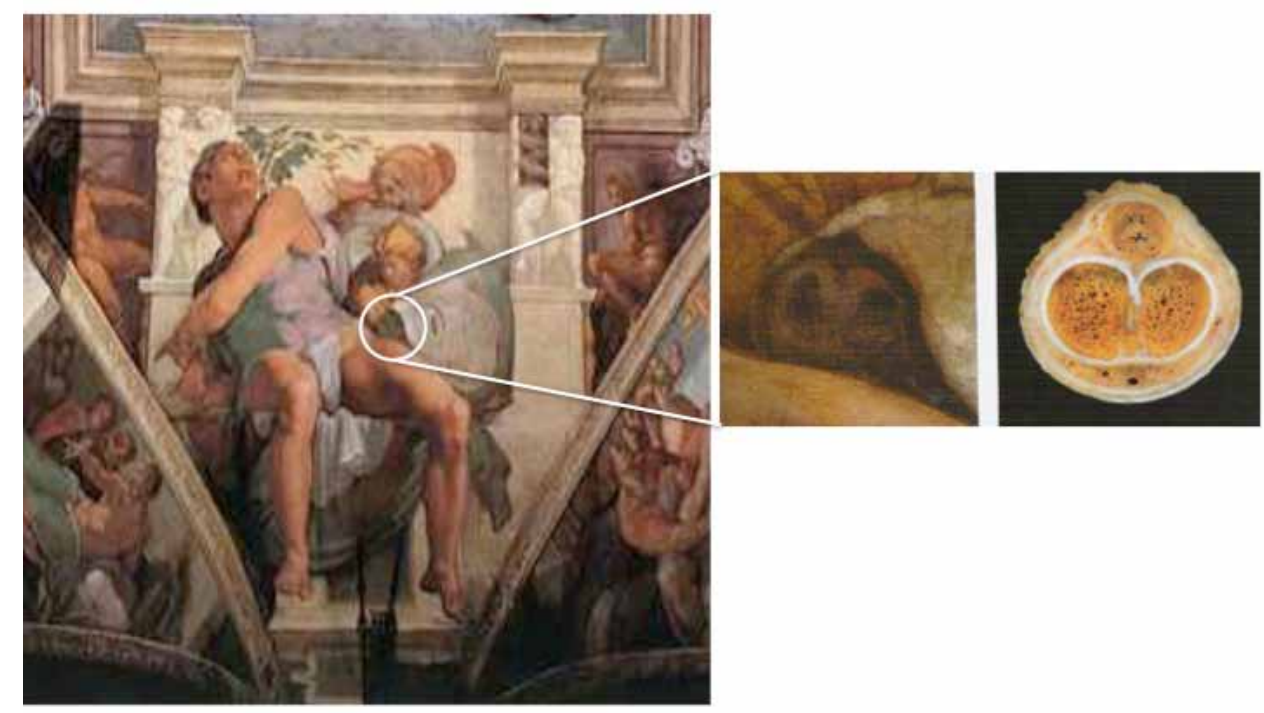


Figure 2 - Michelangelo Buonarroti reveals the genital focus in a draft of the scene not maintained on the original painting of the ceiling of Sistine Chapel. The study shows the Prophet Jonah with the right hand over the genital area.

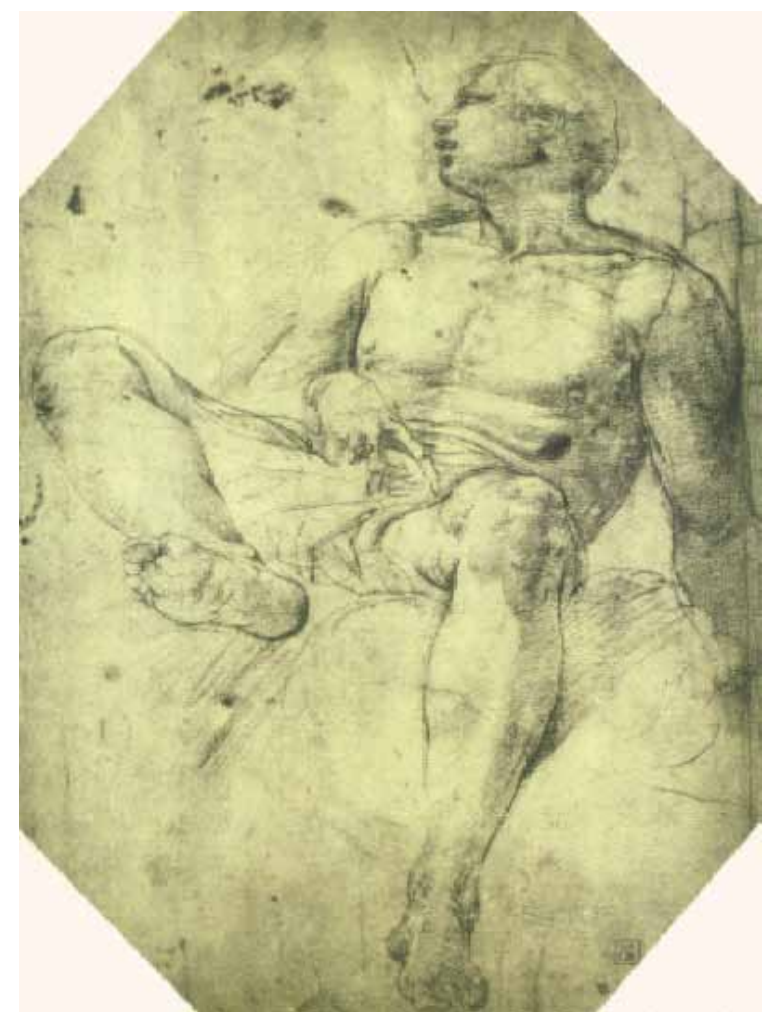

church. Permission to dissect corpses, provided the remains were buried decently, had been granted by Pope Sixtus IV, who had been a student at the Medical School of Bologna (9-15). While some of the more daring artists performed actual dissections, most participated in public anatomies conducted by physicians versed in the art of dissection and accompanied by reading and interpretation of medical texts by the physician-anatomist (4,9-11).

Michelangelo probably participated in public dissection early in his youth, probably conducted by Elia del Medigo, a physician-philosopher who was a member of Lorenzo de Medici's circle, which Michelangelo joined in his mid teens (2-4). Michelangelo began to perform his own dissections and demonstrations, as recorded by his two biographers, Vasari and Condivi $(1,8,16)$. He is said to have made molds of muscles to experiment in their shapes and forms during various body positions, which he was to render so masterfully in his subsequent sculpture and painting. This is clearly evident in the 20 nude slaves ("ignudi"), seated on blocks above the thrones of the "Sibyls" and "Prophets", that decorate the small panels of the Sistine Ceiling and in more than 300 figures that he painted in the "Last Judgment", which, according to Vasari, was intended to represent "the most perfect and well-proportioned composition of the human body in its most varied positions" $(1,17)$.

Beginning in 1492, Michelangelo did most of his dissections at the Monastery of Santo Spirito to whose prior, Fra Niccolo Bichiellini, he made the gift of a wooden crucifix (7). According to both Vasari and Condivi, one of the foremost anatomists of the Renaissance, Matteo Realdo Colombo (15161559), was a close Michelangelo's acquaintance. Condivi stated that at one point, Colombo even sent a corpse to Santa Agata for Michelangelo to dissect. We can only guess as to the depth of Michelangelo's anatomic knowledge because he did not publish any detailed drawings of his cadaver dissections. It is reported that he probably destroyed his numerous anatomic sketches and notes (18). Only a few sketches of his anatomic studies have survived, and these are limited to depictions of musculoskeletal or topographic anatomy (19).

Barring the discovery of additional literary documentation, it is impossible to know exactly how much knowledge of anatomy Michelangelo had (19). Robert Beverly Hale has remarked that anyone today can know as much anatomy as Michelangelo did by studying it for several years and doing a few dissections. Any textbook will quickly provide information that Michelangelo had to work years to get (20). In this context, it is imputed to Michelangelo the phrase: "To paint a fish, buy a fish, to paint a man, dissect a man".

About Michelangelo's achievement there are doubts whether we ascribe the forms in his figures to knowledge of dissection or (what is even less tenable) to expressive and free distortion and invention. Where Michelangelo excelled beyond what we can do was in a quality so simple it escapes the sieves of scholarship: the ability to observe. Some authors believe that the anatomic accuracy of his figures is not due to dissection but to observation, and in fact the observation is so penetrating that it blocks attempts to isolate the 
other sources of forms, dissection and the Antique. His works exhibit anatomical details that are unobservable upon dissection, like the very important class of cases in which surface contours are produced by active muscles. Since the forms are forms of life, visible on the living body, they are not a closed subject for specialists, but are open to anyone as a new way to approach and appreciate his achievement. Attempts to show how much anatomy Michelangelo knew by analyzing individual unlabeled works simply reinforces the conclusion expressed above that observation, not dissection, is responsible for most surface contours (19).

Inspired in the publications of Meshberger (5) and Eknoyan (7), two authors initiated a detailed analysis of each scene of Sistine Chapel Ceiling looking for anatomical figures hidden in the main image (21). The authors believe that Michelangelo uses a number of resources to make this intention clear. The code - or set of iconographic and pictorial clues - is present not only inside the scene, but also in its adornments and they indicate some aspects that must be observed inside the scenes: the position of the figures, which often indicates the part of the body that Michelangelo "camouflaged" at some other point (in most cases, in the folds of the garments); the direction they are looking to; the "movement" of the hands, which often points to the hidden anatomical part; the region of the body that is painted in lighter shades. The deciphered code is present in each of the thirty-two scenes analyzed by authors (21). Specifically in the scene of Prophet Jonah, although not maintained on the original painting, a draft reveals the genital focus (Figure-2).

Some critiques believe that the references to the studies of anatomy of Michelangelo, emphasized by the authors, although needed for the argument, are not enough to sustain it (22). Besides, there is not a characterization of the period in question that supports the interpretations offered in order to approximate the culture of the Renaissance to documents as texts and drawings from Michelangelo's contemporary artists. This approximation becomes necessary to be able to find the cognitive style of an epoch. As the Michelangelo's frescoes in Sistine Chapel are anatomical tridimensional forms, many, according to the angle which are seen, serve both to interpretations of the authors as to many others, according to good will and creativity of the viewer, which in some cases, have to be extraordinarily strong. Thus, according to critiques, there would be no reason to think that in a series of frescoes with a distinctly theological plane, Michelangelo represented anatomical forms (22).

Nephrologists, of course, may be especially apt to see kidney shapes. Similarly, neurologists tend to see the shape of a human brain (5). In summary, it seems that Michelangelo's creative depictions of human body allow for physicians from varied specialties to identify with different aspects of his work.

Regarding scientific and subjective criteria adopted in this study rational, considering the circumstances in which Michelangelo have painted the ceiling of the Sistine Chapel, subjectivity was fundamental due to religious motivations added to the vigorous implications of a limited scientific knowledge typical of that era.

On the other hand, if this is the best one can do when studying art and history in a reality far away along the time line, it is not a strong enough motivation to ignore or to do not reflect over the important creations of the remote past. Furthermore, noting Santayana's sentiments "those who forget history are condemned to repeat it". And given the Michelangelo reputation and the importance of his works we are privileged to be able to access lots of credible documents.

The study does not have the pretension to definitively prove our hypotheses, which may be impossible considering the age and circumstances of the facts discussed. However, we consider the presented manuscript a hypothesis generating. In this context, hopefully, astute observations (even historical) can add to our current understandings; they exercise shrewd observation skills and a curious analytical mind to understand unexplained features of a given circumstance, providing the bases and rational for future researches that will lead to "intelligent design" and evidence-based behavior.

It is clear that this study is beyond the science and aggregates art and history and since art interpretation is subjective, the quest will doubtless 
continue (23). As mentioned by Suk and Tamargo (6) at the conclusion of their article "In art history, there are few opinions that stand undisputed, and most are sustained by either circumstantial evidence or simply by the cumulative analyses of observers, because artists do not issue their works with an explanatory text”.

\section{CONCLUSIONS}

This description helps to confirm the relationship of the Renaissance artist and his relationship with the human anatomy; science has been much studied in this period. We reveal the presence of the design of a cross section of the penis with the two cavernous bodies with the septum between them and the spongy body, in the ceiling of the Sistine Chapel painted by Michelangelo Buonarroti between the years 1508 and 1512 .

Partially presented as abstract/podium (\#1136) in the American Urological Association's (AUA) 2010 Annual Scientific Meeting, San Francisco, CA, USA. Reis LO, Barreto G. The Interpretation of the Figure of the Prophet Jonah by Michelangelo on the Ceiling of the Sistine Chapel: Anatomical Urological Vision. J Urol. 2010 183:4; Suppl. e439-e440. LINK: http://webcasts.prous. $\mathrm{com} / A U A 2010 / \mathrm{html} / 1$ - en/teplate.aspx?section $=2$ octidl $=11911$ \&teid $=643$

\section{CONFLICT OF INTEREST}

None declared.

\section{REFERENCES}

1. Vasari G. The Lives of the Artists. Oxford: Oxford University Press. 1991.

2. Hughes A. Michelangelo. London: Phaidon Press Limited. 1997.

3. Kristeller P0. Eight Philosophers of the Italian Renaissance. Stanford: Stanford University Press. 1964.

4. Summers D. Michelangelo and Language of Art. Princeton: Princeton University Press. 1981.

5. Meshberger FL: An interpretation of Michelangelo's Creation of Adam based on neuroanatomy. JAMA. 1990; 264: 1837-41.
6. Suk I, Tamargo RJ: Concealed neuroanatomy in MichelangeIo's Separation of Light From Darkness in the Sistine Chapel. Neurosurgery. 2010; 66: 851-61; discussion 860-1.

7. Eknoyan G: Michelangelo: art, anatomy, and the kidney. Kidney Int. 2000; 57: 1190-201.

8. Condivi A: The life of Michelangelo. Baton Rouge: Louisiana State University Press; 1976.

9. Mayor AH. Artists and Anatomists. New York: The Metropolitan Museum of Art; 1984.

10. Schultz B. Art and Anatomy in Renaissance Italy. Ann Arbor: UMI Research Press; 1982.

11. Vasari G. Vasari on Technique. New York: Dover Publications Inc; 1960.

12. Cunningham A. The Anatomical Renaissance: The Ressurrection of the Anatomical Projects of the Ancients. Hants: Scholar Press; 1997.

13. Moe $\mathrm{H}$. The Art of Anatomical Illustration in the Renaissance and Baroque Periods. Copenhagen: Rhodes; 1995.

14. Margotta R. The History of Medicine. New York: Smithmark Publishers; 1996.

15. Wittkower R, Wittkower M: Born Under Saturn. The Character and Conduct of Artists: A Documented History from Antiquity to the French Revolution. New York: W.W. Norton; 1963.

16. Partridge L. Michelangelo. The Sistine Chapel Ceiling. Rome, New York, G. Brazilier; 1996.

17. Steinberg L: A corner of the Last Judgement. Daedalus. 1980; 109: 207-73.

18. Eknoyan G, De Santo NG: Realdo Colombo (1516-1559). A reappraisal. Am J Nephrol. 1997; 17: 261-8.

19. Elkins J: Michelangelo and the human form: his knowledge and use of anatomy. Art Hist. 1984; 7: 176-86.

20. Hale RB, Coyle T: Anatomy Lessons of the great masters (Practical art books). Watson-Guptill; 1977.

21. Barreto G, Oliveira MG: The Secret Art of Michelangelo: a lecture of anatomy in the Sistine Chapel. 4th ed. São Paulo (Brazil): Arx; 2004.

22. Kickhöfel EHP: Uma falsa lição de anatomia ou de um simples caso de impregnação teórica dos fatos. Scientiae Studia, São Paulo. 2004; 2: 427-43.

23. Strauss RM, Marzo-Ortega H: Michelangelo and medicine. J R Soc Med. 2002; 95: 514-5.

Correspondence address Dr. Leonardo Oliveira Reis

Faculty of Medical Sciences, University of Campinas, Unicamp Rua Tessália Vieira de Camargo, 126 Cidade Universitária "Zeferino Vaz" Campinas - SP - Brasil - CEP: 13083-887 Phone/Fax: + 5519 3521-7481 E-mail: reisleo@unicamp.br 


\section{EDITORIAL COMMENT}

It is well documented that there have always been a close and subjective relationship between science, medicine and art, especially during the Renaissance. This can be evidenced in many of Michelangelo's frescoes, such as in "Creation of Adam" and "Separation of Light From Darkness", all of them painted on the ceiling of the Sistine Chapel.

Analyzing "human history archives" retrospectively, it is evident that medical sciences did not become an object of devotion in a short period of time. Approximately 2.500 years have certainly passed until Medicine becomes a recognized and respectful science, as it is seen nowadays. Not surprisingly, many individuals from different ethnic origins and characteristics have had a relevant, irrelevant and even a detrimental role in developing the knowledge we see in actual medical textbooks. It is also important to highlight that many individuals have sacrificed their own lives towards this knowledge.

During this period, Hippocrates, in Ancient Greece, Galeno, during Roman Empire and Ibn Sina (Avicena) during Middle Ages, have developed the understanding of human physiological functions based only on morphological aspects. In Ancient Times, surgery and dissections were considered a drastic intervention and they were only limited to human surfaces. The advent of Scientific Revolution, commonly dated from Renaissance or 17th century, has certainly played an important role in developing more ra- tional human thoughts against the magical and miraculous ones, although these thoughts were still limited to the existing knowledge. It is interesting to observe that it is exactly in this period of history that the objective and discussion of this article is based on.

The authors' detailed analysis of a possible design of a cross-section of the penis in "Prophet Jonah" fresco on the Sistine Chapel, created by the Italian Renaissance artist Michelangelo Buonarroti, is obviously a subjective and hypothetical interpretation. However, the nature of art interpretation and creativity is definitely subjective and maybe this is the exact point that turns art into an admirable and astonishing subject. In this regard, one of the ways that best summarizes the interpretation link between art and science subjectivity, as can be evidently observed in the current paper, is this famous Hippocrates quote "Life is short, the art long, opportunity fleeting, experiment treacherous, and judgment difficult".

Dr. Ernani Luis Rhoden

Professor of Urology

Universidade Federal de Ciencias da Saúde de Porto Alegre (UFCSPA)

Florencio Ygartua 288/504

Porto Alegre, RS, 90030-010, Brazil

Fax: + 5551 3333-3144

E-mail: ernanirhoden@yahoo.com.br

Dr. Graziele Halmenschlager Professor of Biomedicine, Universidade Ritter dos Reis (UniRitter) 